\title{
Particle Physics ANd The CONSCiOUS Mind: Debating Almada's OPTIMISM
}

\author{
[ Física de PARTículas E MENTE CONSCIENTE: DEBATENDO o otimismo de Almada ]
}

\author{
César Fernando Meurer * \\ Universidade Federal de Uberlândia, Brasil
}

\begin{abstract}
Beginning with a study of the basic components of the physical world, Almada is developing an explanation of the emergence of the conscious mind. In order to recognize and publicize this enterprise, which is not yet finished, this note (i) offers an overview of Almada's approach; (ii) challenges his optimism with the well-known hard problem of consciousness; and (iii) argues that his research can be pushed ahead by a coherent conceptual account of emergence.
\end{abstract}

KEYwords: Standard Model of Particle Physics; Emergentism; Neurophenomenology
RESUMo: Começando com um estudo dos componentes básicos do mundo físico, Almada está desenvolvendo uma explanação da emergência da mente consciente. Com a intenção de reconhecer e publicizar esse empreendimento, que ainda não está concluído, a presente nota (i) oferece uma visão geral da abordagem de Almada; (ii) desafia o seu otimismo com o conhecido 'hard-problem' da consciência; e (iii) argumenta que a sua pesquisa pode ser levada adiante mediante um conceito coerente de emergência.

Palavras-Chave: Modelo Padrão da Física de Partículas; Emergentismo; Neurofenomenologia

1mada's recent publications $(2017 \mathrm{a} ; 2017 \mathrm{~b})$ are somewhat unusual in A the Brazilian philosophical scene: a) these two pieces are the first outcomes of a larger investigation on consciousness; b) this investigation, which will be published in a longer series of papers, aims at developing a new perspective in the philosophy of mind; and c) it seeks to be thoroughly empirically informed. All of this is positive and very encouraging for scholars that are interested in addressing problems in a more interdisciplinary and empirically informed way.

The main aim of this note is to recognize and publicize Almada's enterprise. I will [1] offer an overview of his approach; [2] challenge his optimism with a version of the well-known hard problem of consciousness; and [3] argue that a coherent conceptual account of emergence will strengthen his research.

* Doutor em Filosofia pela Universidade do Vale do Rio dos Sinos (Unisinos, 2016). Postdoctoral Visiting Scholar no Departamento de Filosofia da Università Degli Studi di Milano, Milão, Itália (2017-18). Pós-doutorando (PNPD/Capes) junto ao Programa de Pós-Graduação em Filosofia da Universidade Federal de Uberlândia(2018-...).m@ilto: cfmeurer@yahoo.com.br 


\section{ALMADA'S APPROACH}

For Almada (2017a), understanding the constitution of the physical world is foundational to understanding consciousness: "[T]he lack of a well-defined delineation of the basic physical components of the world and hence of the organisms' composition", he writes, "is perhaps what explains the multiplicity of perspectives - often incompatible with each other - concerning the nature and the ontological status of the conscious mind, and the place of the mind in the natural world" (2017a, p. 110-111).

Almada believes a proper understanding of the basic components of the natural world will highlight emergentism as the best framework for the research on consciousness (Almada, 2017b). Along this line, he praises the Standard Model of Particle Physics as "very successful in mapping almost all properties and interactions of the basic constituents of the visible matter in the universe at its most fundamental level" (2017a, p. 118; See also 2017b, p. 75-76). In short, this model holds that (1) the physical world is made up by elementary particles, fundamental forces, mediating particles, and antiparticles; (2) the elementary particles are fermions (different kinds of quark) and leptons of different types and generations; (3) the elementary particles interact by means of four fundamental forces: the electromagnetic, the strong, the weak, and the gravitational force; (4) the elementary particles also interact with the mediating particles; (5) the mediating particles are photons (mediators of electromagnetic interaction), gluons (mediators of strong force), the bozons $W$ and $Z$ (mediators of weak force), the Higgs boson (considered responsible for the origin of the mass that elementary particles have), and the graviton (hypothetically the mediator of gravitational force); (6) the antiparticles are counterparts of the elementary particles in the following sense: every particle has an antiparticle with the same mass but with opposite charge.

Almada conceives of particles "as excitations of quantum fields" (2017a, p. 120 ), and not as atoms in the classical sense. (For a critical discussion of atomism and mechanicism, see $2017 \mathrm{~b}$, p. 83-86). I entirely agree with him on this nonatomistic point of view: it makes room for quantum field theory and signals compatibility with special relativity (See Zee, 2010). Furthermore, it counts as a clear evidence of the empirically informed philosophy of mind he is pursuing.

Despite the success, the Standard Model of Particle Physics has at least one major limitation: it does not fully account for gravitational force. Almada acknowledges this fragility and asks: "Is there a role for gravitational force in human consciousness studies?" (2017a, p. 124). Given that gravity "acts universally in all matter and energy", it is quite obvious that it has a dominant role "in the physiological mechanisms behind the constitution of self-consciousness at its most primordial level” (2017a, p. 125; See Pozzo et al. 1998).

At this point, Almada's optimism emerges: on the one hand, the model he adopts has no consolidated account for gravitational force at the physical level; on the other, he is willing to recognize not only that "gravity has shaped the architecture, form, and function of the biological systems, or even the very life on Earth" (2017a, p. 129), but also that

we cannot neglect the gravity to support a complete philosophical position on the problem of consciousness-mind-self-encephalon-body-environment relation, particularly with regard to the investigations both on the role of corporeality (including information channels) and the environment in the understanding of 
how the (conscious) mind emerges from an organism embedded in and interacting with its environment (Almada, 2017a, p. 130).

Almada's second paper (2017b) defends two connected ideas: (i) that the natural world has hierarchical levels of complexity, and (ii) that emergent properties are irreducible to anything else. Two philosophical convictions, so to say, support this defense: that both reductive and non-reductive physicalism have failed to overcome dualism (2017b, p. 78-81), and that emergentism is currently the best theoretical option for philosophers of mind focused on consciousness (2017b, p. 81-83 and p. 89).

Given the above-mentioned non-atomistic view of particles, higher levels of complexity in the natural world cannot be explained in terms of presence or absence of material constituents. Instead, they are distinguishable by their ability to display ontological novelties $(2007 \mathrm{~b}$, p. 83). In light of this, the big picture becomes clear: (a) there is a basic physical level, which is described by the Standard Model of Particle Physics in terms of particles, forces, and antiparticles; (b) there are processes of self-organization; (c) these processes bring about systemic and emergent properties; (d) a new emergent property inaugurates a new level, which is more complex than and irreducible to the previous one; (e) at each new level, other processes of self-organization take place; (f) at a sufficiently high level, mental properties emerge; (g) at an even higher level, consciousness emerges.

The starting point of a bottom-up explanation - one that goes from (a) to (g) - is somewhat compromised due to the above mentioned difficulties regarding gravity. Furthermore, no bottom-up explanation will ever suffice because higher levels regulate and restrict processes at the lower levels: "Lower-level components depend on the higher-level properties, since the organizational pattern [of a higher level] changes the relations that the parts have with each other, as well as modifies the causal powers of the parts themselves" (Almada, 2017b, p. 87). Thus, in order to complement bottom-up analyses, a top-down explanation is expected (See Bunge, 2010). In the next section, Almada's optimism about the feasibility of this approach is challenged.

\section{Challenging Almada's OPTimism}

Since Chalmers (1995), the challenges of scientific research on consciousness have often been classified into easy and hard problems. On this view, explaining the relevant physical states and processes related to consciousness turns out to be relatively easy because it handles problems "that seem directly susceptible to the standard methods of cognitive science, whereby a phenomenon is explained in terms of computational or neural mechanisms" (Chalmers, 1995, p. 200). Explaining the raise and the very nature of the subjective aspect of experience is hard because it seems untouchable by the methods of cognitive science. Moreover, subjective experience may continue to be a mystery after the ultimate explanation of all the easy problems.

Accepting that first-person experience is irreducible to anything else, Varela (1996) has proposed a methodology to address the hard problem: neurophenomenology. Basically, this proposal "seeks articulations by mutual constraints between the field of phenomena revealed by experience and the correlative field of phenomena established by the cognitive sciences" (p. 347). In 
other words, it aims at integrating "objective and subjective data in ways that retain the statistical power of established disciplines (like cognitive science) while embracing the value of first-person reports of experience" (Bockelman, Reinerman-Jones and Gallagher, 2013, p. 01).

It is debatable whether neurophenomenology is an effective remedy for the hard problem, as the title of Varela's (1996) influential paper suggests. First, it builds on first-person reports and these are conceptually, epistemologically, and methodologically controversial. Thompson, Lutz, and Cosmelli (2005, p. 40-41) describe these controversies in terms of a triple explanatory gap:

An adequate conceptual framework is still needed to account for phenomena that (i) have a first-person, subjective-experiential or phenomenal character; (ii) are (usually) reportable and describable (in humans); and (iii) are neurobiologically realized; $[. .$.$] the generation of first-person data raises difficult epistemological$ issues about the relation of second-order awareness or meta-awareness to firstorder experience; [...] The need for first-person data also raises methodological issues (e.g., whether subjects should be naïve or phenomenologically trained).

Considered in terms of Almada's hierarchical levels of complexity (See section [1]), first-person reports are data coming from a very high and complex level of organization. They are, therefore, describable as an important ingredient of a top-down explanation. Considering that this ingredient may be conceptually, epistemologically or methodologically compromised, what makes first-person reports reliable for a scientific approach to consciousness? Are there other types of data (other than first person reports) that could supply a top-down analysis?

Second, neurophenomenology addresses a problem that has two related explanatory targets: "the first concerns explaining the relationship between physical processing and phenomenally conscious experiences, whereas the second involves explaining the very nature of phenomenal consciousness itself" (Majeed, 2016, p. 298). Importantly, Majeed notices that the first target "involves not just identifying which physical processes are the correlates of our phenomenally conscious experiences, but explaining how and why they result in such experiences" (p. 299). As for the second target, it "is equivalent to explaining the very thing, phenomenal character, itself. This in turn is to be understood as explaining not just individual phenomenal qualities, e.g. the way red seems to us, but the nature of phenomenal character in general as well" (p. 299). In light of section [1], perhaps a bottom-up explanation of the emergence of consciousness counts for an explanation of the very nature of consciousness as well (Majeed's second explanatory target)?

To sum up, Almada conceives the world as hierarchically stratified, thanks to processes of self-organization and emergent properties. In this world, the conscious mind happens to emerge at a high and complex level of organization. $\mathrm{He}$ optimistically thinks that this event - the conscious mind - can be explained by means of a combination of bottom-up and top-down analyzes. This raises two questions: Are first-person reports reliable ingredients of top-down explanations? Is the explanation of the emergence of the conscious mind expected to inform about the nature of the conscious mind? In the next session, I will suggest that Almada's approach can be pushed ahead by a coherent conceptual account of emergence. 
'Emergence' refers the idea that something new (a property, a phenomenon etc.) arises out of something more basic, though it is irreducible to that base. According to Almada (2017a), the conscious mind "emerges in organisms with nervous systems of sufficient complexity to instantiate the conscious life" (p. 109) as long as they are "embedded in and interacting with its environment" (p. 130). The development of this line of reasoning includes an explanation of the emergence of life as such and, in a subsequent step, the emergence of conscious life. This, I submit, calls for a philosophically rigorous and empirically useful definition of emergence.

Given both the Standard Model of Particle Physics and the biological importance of gravity, life as such has to be something that emerges out of a certain arrangement of particles, forces, and antiparticles. What can be said about this happening? Indeed, Almada allows his reader to expect some words on the emergence of life. Does he accept the idea that biological properties such as sensitivity to the environment, reproduction, growth and development, homeostasis, energy processing etc. are emergent properties?

The complexity of the nervous system is, in Almada's view, a conditio sine qua non for conscious life. This can be interpreted as meaning that the emergence of conscious life presupposes certain mental properties (See 2017b, p. 76) and these, in turn, presuppose certain biological properties. So, if emergence really is such a widespread phenomenon, then the conceptual account I'm insisting upon should be useful to distinguish genuine from non-genuine cases.

Given that Almada aspires to build "an emergentist theoretical model" $(2017 \mathrm{~b}, 76)$, does he take emergence as a real feature of the world or just as a feature of his model? If emergence is not an objective feature of the world, then it may be seen as "a result of our imposing certain kinds of representation on the world, or a result of our limited abilities to comprehend correctly what the world is like" (Bedau and Humphreys, 2008, p. 05).

Scientific models are typically evaluated in their ability to explain past facts, on the one hand, and in their ability to predict new facts, on the other hand. So, assuming that an emergentist model of consciousness is meant to explain a past fact (the emergence of the conscious mind), one may ask: can it also predict the emergence of new properties or phenomena? I wonder whether Almada conceives emergent properties as explainable and predictable or as explainable and unpredictable. Unpredictability, in this case, may mean a temporary lack of knowledge. In Hempel and Oppenheim's (1948, p. 150-151) words:

Emergence of a characteristic is not an ontological trait inherent in some phenomena; rather it is indicative of the scope of our knowledge at a given time; thus it has no absolute, but a relative character; and what is emergent with respect to the theories available today may lose its emergent status tomorrow.

Finally, there is the intricate debate on the causal power of emergent properties. If emergence is a real feature of the world (and not just a feature of a model), and if at a certain level of complexity mental properties do emerge, and if these properties are prerequisites for the emergence of other properties, then one has to explain both the descendent and an ascendant role such properties play. Would it be correct to say that an emergent property constitutes an additive condition for higher levels and a subtractive condition for lower levels?

In this section, I have presented some of the reasons why I think Almada's research would greatly benefit from a conceptual clarification of emergence. To 
conclude: Almada's efforts towards a new perspective in the philosophy of mind deserve recognition and dissemination.

\section{REFERENCES}

ALMADA, L. F. In search of the theoretical and conceptual foundations of the mind-problem: what does physics have to say about the basic constitution of the world? Philósophos, v. 22, n. 1, p. 107-140, 2017. (quoted as 2017a) http://dx.doi.org/10.5216/phi.v22i1.41954

ALMADA, L. F. The mind-body problem from an emergentist approach: a defense of physicalism based on the levels of complexity of the nature and on the irreducibility of emergent properties. Dissertatio, v. suppl. 5, p. 73-97, 2017. (quoted as 2017b)

BEDAU, M.; HUMPHREYS, P. Introduction. In: BEDAU, M.; HUMPHREYS, P. (Eds.) Emergence: contemporary readings in philosophy and science. Cambridge, MA: The MIT Press, 2008. p. 01-06. http://dx.doi.org/10.7551/mitpress/9780262026215.001.0001

BOCKELMAN, P.; REINERMAN-JONES, L.; GALLAGHER, S. Methodological lessons in neurophenomenology: review of baseline study and recommendations for research approaches. Frontiers in Human Neuroscience, v. 7, article, 608, p. 01-09, 2013. https://doi.org/10.3389/fnhum.2013.00608

BUNGE, M. Matter and mind: a philosophical inquiry. New York: Springer, 2010.

CHALMERS, D. Facing up to the problem of consciousness. Journal of Consciousness Studies, v. 2, n. 3, p. 200-219, 1995.

HEMPEL, C.; OPPENHEIM, P. Studies in the logic of explanation. Philosophy of Science, v. 15, n. 2, p. 135-175, 1948. https://doi.org/10.1086/286983

MAJEED, R. The hard problem \& its explanatory targets. Ratio, v. 29, n. 3, p. 298-311, 2016. https://doi.org/10.1111/rati.12103

POZZO, T.; PAPAXANTHIS, C.; STAPLEY, P.; BERTHOZ, A. The sensorimotor and cognitive integration of gravity. Brain Research Reviews, v. 28, n. 1-2, p. 92-101, 1998.

THOMPSON, E.; LUTZ, A.; COSMELLI, D. Neurophenomenology: an introduction for neurophilosophers. In: BROOK, A.; AKINS, K. (Eds.) Cognition and the brain: the philosophy and neuroscience movement. New York: Cambridge University Press, 2005. p. 40-97.

VARELA, F. Neurophenomenology: a methodological remedy for the hard problem. Journal of Consciousness Studies, v. 3, n. 4, p. 330-349, 1996.

ZEE, A. Quantum field theory in a nutshell. Princeton: Princeton University Press, 2010. 